\title{
A photovoltaic power generation system with peak cut function
}

\author{
Mohammed A. Bou-Rabee ${ }^{a^{*}}$, Dong-Hwa Han ${ }^{b}$, Gyu-Ha Choe \\ ${ }^{a}$ PAAET Dept. of Electrical Eng. College of Technological Studies Kuwait \\ ${ }^{b}$ Electrical Eng. Konkuk University, Seoul, Korea
}

\begin{abstract}
This paper presents a photovoltaic-peak power cutting (PV-PPC) system capable of cutting peak load power. The proposed system is composed of a PV generator, DC-DC converter, storage battery, and an inverter. The function of the proposed PV-PPC system is to use PV energy to cut the peak load power in response to the change in the load demand and generating power. Four possible power flow scenarios are examined in detail through the bidirectional operation of the DC-DC converter and inverter, through the charging and discharging of the battery. The suggested PV-PPC system operation algorithm first selects the operational state by using differentiated charge and load information, with a simple structure to enable stopping in case of system failure, and operates depending on the selected state. Then, the analysis modeling and operational control algorithm of the PV-PPC generation system are performed in detail. Finally, the simulation and experimental results are presented to confirm the validity of the system.
\end{abstract}

Keywords: PV system, peak power cut, battery, photovoltaic-power conversion system

\section{Introduction}

Nowadays, the interest in clean energy sources is a focus in countries across the world due to the environmental pollution caused by fossil fuels. PV, wind, fuel, and biomass are becoming promising sources of clean energy for the future. [1]-[3] Moreover, the Kuwait government declared a policy of 'Lower Carbon and Green Growth' for the national development of renewable energy. PV energy, among all of these new regeneration energies, has the advantage to minimize the costs of operation and maintenance differently from other new regeneration energies, and studies regarding PV cells and power converters have been actively performed for some time. [4]-[9].

The existing PV-PCS (Photovoltaic-Power Conversion System) is used as an energy source. The algorithm of the existing PV-PCS has a simple structure in that the energy generated from the PV is sent to the grid. Therefore, the existing PV-PCS has the disadvantage that energy generation depends on the value of the PV radiation and temperature.[10]-[12] Therefore, it is impossible to expect a reduction effect on the peak load. A local power failure event occurred on Sept. 15, 2011 in Korea. The power failure event occurred while trying to meet preliminary power by performing a partial power failure in the country, since the preliminary wattage managed by KEPCO (Korea Electric Power Corporation) failed to respond to a sudden increase in load. The above situation suggests that cutting the peak load is important, as well as determining the time and power that the distributed power supplies will generate considering the status of the load.

This study handles the composition and control of the PV-PPC (Photovoltaic-Peak Power Cut) system that has a peak load cutting function by using energy storage devices, and suggests the operation algorithm of the system. In addition, this study intends to verify feasibility through simulation and experimental case studies of the suggested operation algorithm.

\footnotetext{
* Manuscript received April 13, 2013; revised July 6, 2013.

Corresponding author. Tel.: +965 60077567; E-mail address: m.rabee@ paaet.edu.kw.
} 


\section{PV-PPC System}

Fig. 1 represents a block diagram of the conventional PV power generating system as an existing energy source method. In this case, the time that the system can generate power varies depending on the amount of PV radiation, and it has a low use-level. However, since the users of the current PV power generating system endure a low use-level and perform operations accurately for the energy source, the system is operated without actual effect in respect to cutting the peak load, in spite of users' or consumers' actual burden of large costs. Fig. 2 represents the block diagram of the proposed PV power generating system with the peak power cutting function. This system is composed of a simple structure with a battery added, similar to the PV power generating system as an energy source, but the operation method of the system is different due to the addition of the battery. With storage of the PV energy and the system energy in a battery, the system has the peak power cutting function to discharge power when energy amounts requested by the load are greatly increased.

\section{Configuration and Control of PV-PPC System}

The PV-PPC system consists of a DC/DC converter, a battery as an energy storage device, and a DC/AC inverter. The PV-PPC system generates power or charges the battery by using PV energy, depending on the status of the amount of PV radiation and the load. The composition of the power circuits, the modeling, and the control of each part are described as follows.



Fig. 1. Conventional PV system.



Fig. 2. Proposed PV system.

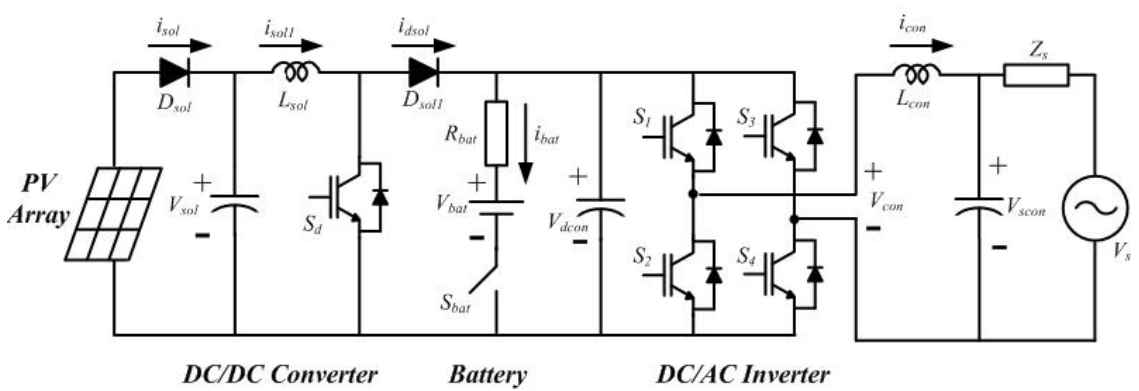

Fig. 3. The power circuit of the PV-PPC system. 


\subsection{Power circuit and modeling of PV-PPC system}

The PV-PPC system shown in Fig. 3 is composed of a DC/DC converter to boost the voltage of the PV, a battery to recharge or discharge the power from the PV or grid, and a DC/AC inverter interconnected to the grid. If applying Kirchhoff's voltage law to the power generation direction from the DC/AC inverter to the system, the voltage equations are expressed as Eqs. (1) through (9), where $v_{s}$ is the grid voltage, $v_{s o l}$ is the PV voltage, $v_{d c o n}$ is the DC-link voltage, $i_{s}$ is the grid current, $i_{s o l}$ is the PV current, and $i_{b o t}$ is the battery current.

$$
\begin{aligned}
& v_{s c o n}=L_{s} \frac{d i_{s}}{d t}+R_{s} i_{s}+v_{s} \\
& C_{c o n} \frac{d v_{s c o n}}{d t}=i_{c o n}-i_{s} \\
& L_{c o n} \frac{d i_{c o n}}{d t}+v_{s c o n}=v_{c o n}\left(=s_{c o n}(t) \cdot V_{d c o n}\right)
\end{aligned}
$$

here, $s_{c o n}(t)=\left\{\begin{array}{cc}1 & \mathrm{~s}_{1}, \mathrm{~s}_{4} \text { on } \\ -1 & \mathrm{~s}_{2}, \mathrm{~s}_{3} \text { on }\end{array}\right\}$; the inverter switching function are:

$$
\begin{aligned}
& C_{c o n d} \frac{d v_{d c o n}}{d t}=i_{\text {sol } 2}-i_{c o n d} \\
& i_{c o n}=s_{c o n}(t) \cdot i_{c o n d} \\
& V_{\text {sol }}=L_{s o l} \frac{d i_{\text {sol } 1}}{d t}+v_{s w} \\
& v_{s w}=v_{d c o n} \cdot\left(1-s_{d c}(t)\right)
\end{aligned}
$$

here, $s_{d c}(t)=\left\{\begin{array}{lll}1 & \mathrm{~s}_{\mathrm{dc}} & \text { on } \\ 0 & \mathrm{~s}_{\mathrm{dc}} & \text { off }\end{array}\right\}$; the boost converter switching function are:

$$
\begin{aligned}
& i_{\text {sol } 2}=i_{\text {sol } 1} \cdot\left(1-s_{d c}(t)\right) \\
& C_{\text {sol }} \frac{d v_{s o l}}{d t}=i_{\text {sol }}-i_{\text {sol } 1}
\end{aligned}
$$

If ignoring the power loss, the instantaneous power balance equation can be expressed as Equations 10 through 12.

$$
\begin{aligned}
& v_{\text {scon }} i_{c o n}+\frac{1}{2} L_{c o n} \frac{d i_{c o n}^{2}}{d t}=v_{c o n} i_{c o n}=-\frac{1}{2} C_{d c o n} \frac{d v_{d c o n}^{2}}{d t}+v_{d c o n} i_{s o l 2} \\
& v_{d c o n} i_{s o l 2}=v_{s w} i_{s o l 1}=-\frac{1}{2} L_{s o l} \frac{d i_{s o l 1}^{2}}{d t}+v_{s o l} i_{s o l 1} \\
& v_{\text {sol }} i_{s o l 1}=-\frac{1}{2} C_{s o l} \frac{d v_{s o l}^{2}}{d t}+P_{\text {sol }}
\end{aligned}
$$

here, $P_{\text {sol }}=v_{\text {sol }} i_{\text {sol }}$

\subsection{Control of PV-PPC system}

\section{1) Control of the DC/DC converter}

The DC/DC converter consists of an MPPT (Maximum Power Point Tracking) control to maximize the power generated in the PV, a voltage controller to control PV voltage ordered by the MPPT control, and a current controller to control the current of the PV, and the details are as follows. Fig. 4 represents the control composition diagram. 
Fig. 4. The control block of the DC/DC converter.
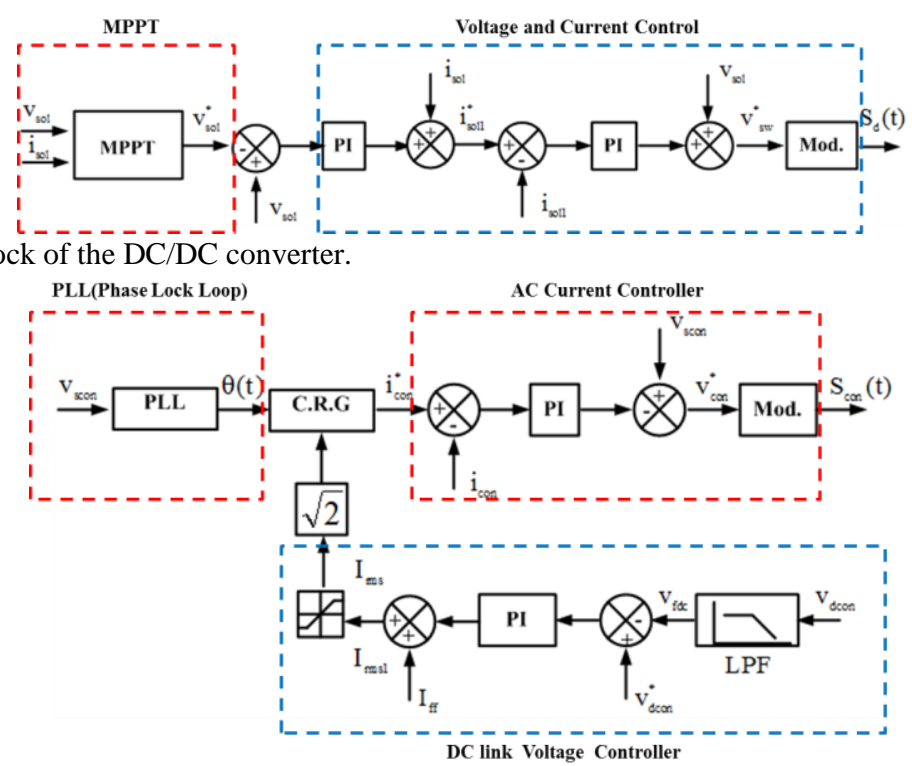

Fig. 5. The control block of the DC/AC inverter.

MPPT control: The MPPT control of the PV is a method to control the power generated in the PV to the maximum, which varies depending on the amount of PV radiation and temperature. This system uses a method of P\&O (Perturbation and Observation) that makes the reference PV voltage increase the direction of the PV power.

Voltage and current controls of the converter: The voltage/current controller of the DC/DC converter consists of a double loop and controls the PV voltage generated from the MPPT control by using the DC/DC converter. Here, the PI controller is used as a voltage/current controller.

\section{2) The control of the DC/AC inverter}

The inverter control consists of the PLL (Phase Lock Loop) to identify the grid phase, DC-link voltage controller to control a constant DC-link voltage for balancing power, and current grid controller. The current controller transfers the PV power to the grid or grid power to the battery. A block diagram to control the DC/AC inverter is shown in Fig. 5.

PLL: The phase of the grid must be known in order to interconnect to the grid. The phase of the grid is determined by using the coordinate conversion of the DQ axis.

DC-link voltage \& grid current controller: The DC-link voltage controller of the inverter transfers power generated in the PV to the grid, and controls the voltage of the DC-link as constant value. The DClink voltage controller creates the reference value of the DC-link current. This is converted as the reference value of the grid current using the grid phase. The PI controller is used to control the voltage and current.

\subsection{The operation algorithm of PV-PPC system}

The PV-PPC (Photovoltaic-Peak Power Cut) system can function to store PV energy or store energy of the system with the battery connected to a DC-link, which is different from the existing PV power generating system that has been used so far. It also has the function to cut the peak load in response to the changes in the load and can reduce electrical charges. For the PV-PPC system with the battery connected, the possible power flow is shown in Fig. 6. The bidirectional operation of the inverter is also available.

The flow of energy, as shown in Fig. 6, represents the (1) storage of PV power in the battery, (2) direct delivery of PV power to the system, (3) generation of energy stored in the battery to the system, and (4) storage of power of the system in the battery. 


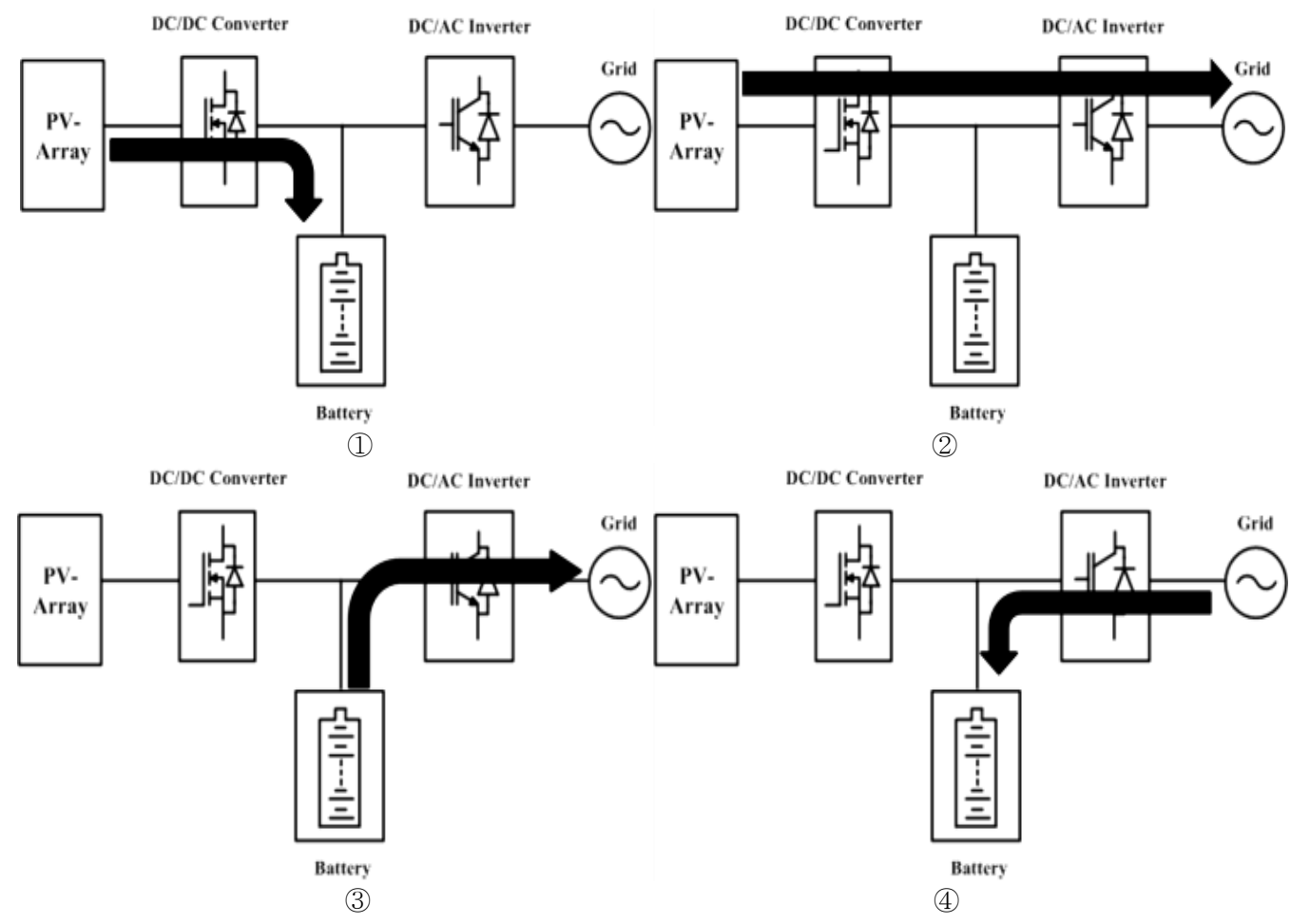

Fig. 6. The possible power flow of the PV-PPC system.

Table 1. The fee schedule of KEPCO by season and time

\begin{tabular}{|c|c|c|c|c|c|}
\hline \multirow{2}{*}{ Type } & \multirow{2}{*}{ Season } & \multicolumn{3}{|c|}{ Time Zone } & \multirow{2}{*}{ Fee rates } \\
\hline & & Light-load & Heavy-load & Maximum-load & \\
\hline \multirow{3}{*}{ Industry } & Summer & $23 \sim 09$ & $18 \sim 23$ & $09 \sim 18$ & $1: 1.9: 2.8$ \\
\hline & Spring and fall & $23 \sim 09$ & $18 \sim 23$ & $09 \sim 18$ & $1: 1.6: 1.9$ \\
\hline & winter & $23 \sim 09$ & $09 \sim 18$ & $18 \sim 23$ & $1: 1.9: 2.3$ \\
\hline \multirow{3}{*}{ Domesticity } & Summer & $23 \sim 09$ & $\begin{array}{l}09 \sim 11, \\
12 \sim 13, \\
17 \sim 23\end{array}$ & $\begin{array}{l}11 \sim 12, \\
13 \sim 17\end{array}$ & $1: 2.2: 3.8$ \\
\hline & Spring and fall & $23 \sim 09$ & $\begin{array}{l}09 \sim 11, \\
12 \sim 13, \\
17 \sim 23\end{array}$ & $\begin{array}{l}11 \sim 12, \\
13 \sim 17\end{array}$ & $1: 1.6: 2.2$ \\
\hline & winter & $23 \sim 09$ & $09 \sim 18$ & $18 \sim 23$ & $1: 2.0: 2.8$ \\
\hline
\end{tabular}

Currently, Korean electrical charges are classified as residential, general education, industry, agricultural, and street light. Among them, industrial use and general use have differentiated charge systems by season and time zone as shown in Table 1 . Pattern information by the time zone of the load for cutting the peak load and differentiated charge information (by season and time zone) for electrical charge saving are required. The suggested PV-PPC operation algorithm first calculates the date and time and selects the state by using differentiated charge information and load information, and is composed of a simple structure where the system stops in failure and operates depending on the selected state.

The suggested PV-PPC operational algorithm first calculates date and time, and then selects state by using different charge and load information. The operational algorithm is composed of a simple structure where the system stops in failure and operates depending on the selected state. Fig. 7 represents the block diagram of the operational algorithm, and Fig. 8 shows the detailed operation by state. Table 2 shows the explanation of Fig. 8 . 


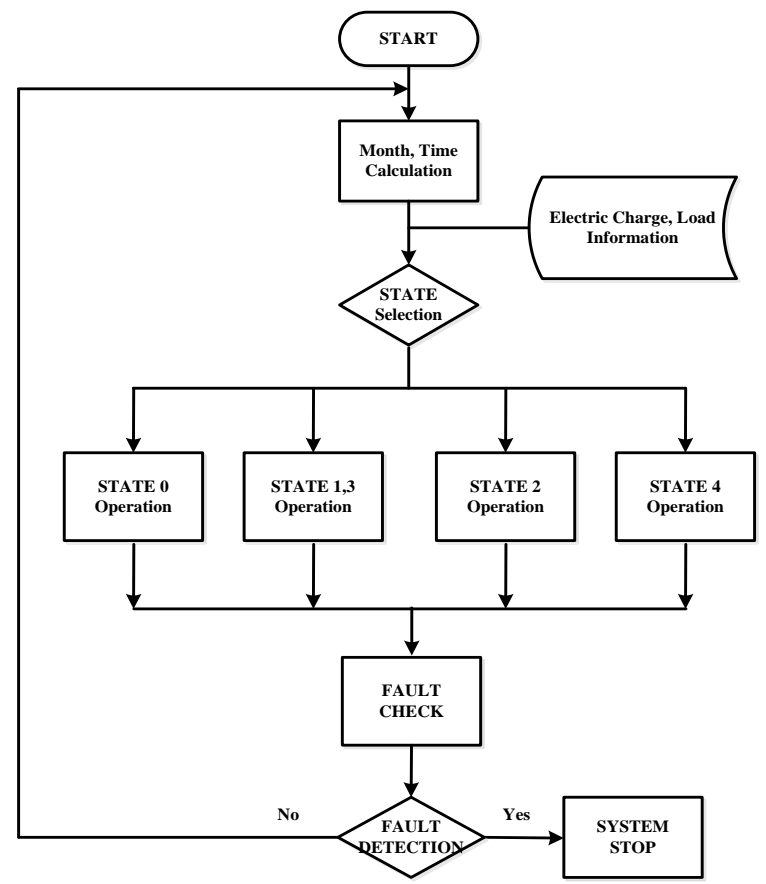

Fig. 7. The operational algorithm of the PV-PPC system.

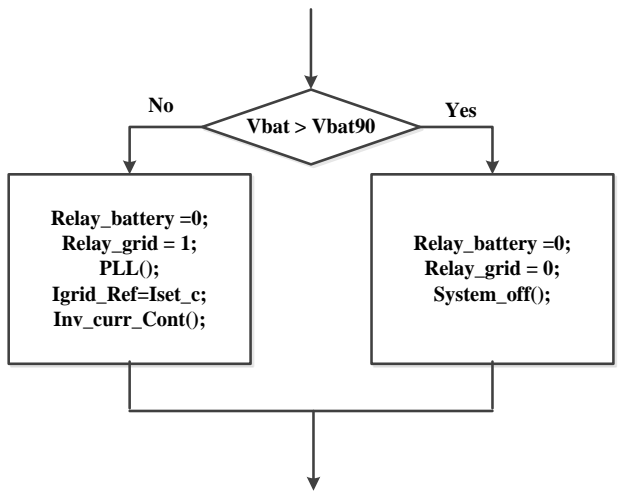

(a) State 0

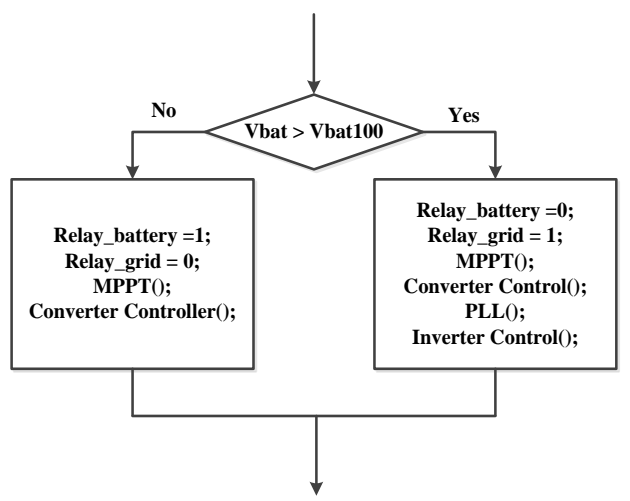

(b) States 1 and 3

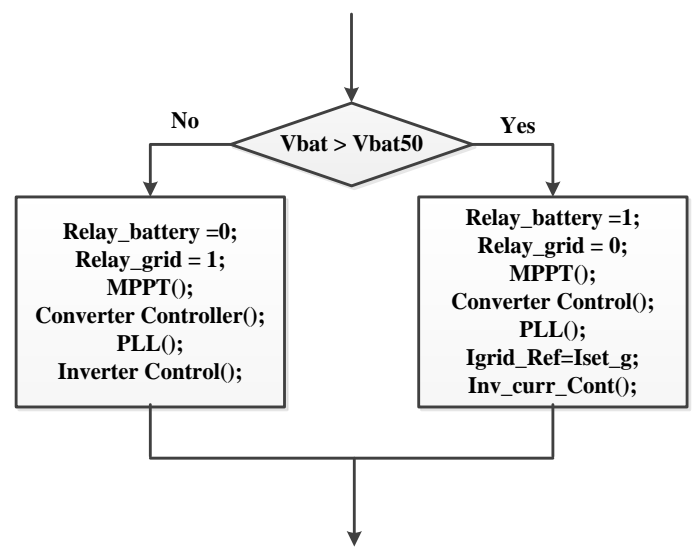

(c) State 2

Fig. 8. The detailed operation by state. 
Table 2. The explanation of Fig. 8

\begin{tabular}{lll}
\hline \hline Notation & Explanation & Remark \\
\hline Vbat & Battery voltage & $\begin{array}{l}\text { Vbat50 : Voltage of 50\% charge state } \\
\text { Vbat90: Voltage of 90\% charge state } \\
\text { Vbat100: voltage of 100\% charge state }\end{array}$ \\
\hline $\begin{array}{l}\text { Relay_battery } \\
\text { Relay_grid }\end{array}$ & $\begin{array}{l}\text { Battery switch } \\
\text { Grid switch }\end{array}$ & $\begin{array}{l}0: \text { Off } \\
1: \text { On }\end{array}$ \\
\hline PLL() & Function of PLL & Tracking the grid phase \\
\hline Converter_Control() & Function of Converter control & $\begin{array}{l}\text { This function consists of MPPT, voltage and current } \\
\text { controller. }\end{array}$ \\
\hline Inverter_Control() & Function of Inverter control & This function consists of voltage and current controller \\
\hline System_off() & System off & System Stop \\
\hline Igrid_Ref & Reference value of grid & $\begin{array}{l}\text { Iset_c : charging current } \\
\text { Iset_g: generating current }\end{array}$ \\
\hline \hline
\end{tabular}

STATE 0: This is the time to charge the battery by using cheap electricity at night. During this time, the relay of the grid and the battery must turn on to connect the system and the battery to the grid, and current control of the inverter must be performed by establishing current to recharge the battery from the system according to the voltage phase of the system. If the voltage of the battery becomes the reference value ( $90 \%$ of the complete recharge), operation STATE 0 is completed.

STATES 1 and 3: This is the time that PV power generation is possible, but the load is not peak load. During this time, the power generated by the PV charges the battery, and if the battery is completely charged, battery charging stops and the PV power is generated to the grid.

STATE 2: This is the peak load time. The power of the battery and the PV is generated toward the grid. In this state, the relays of both the battery and grid system remain on.

If the voltage of the battery drops below a constant value (50\% of complete recharging voltage), the relay of the grid is turned off and the battery is charged by PV power.

STATE 4: There is no operation in this state.
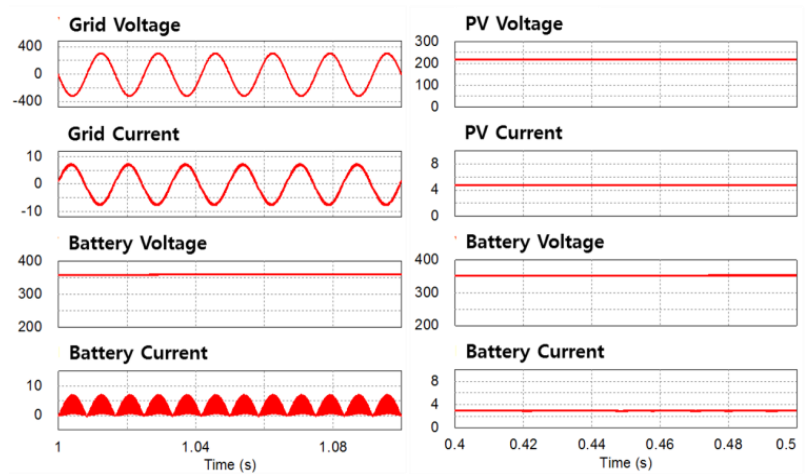

(a) State 0

(b) States 1 and 3 (Battery charging)

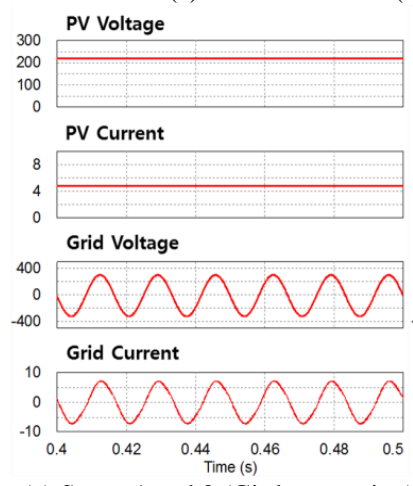

(c) States 1 and 3 (Gird generating)

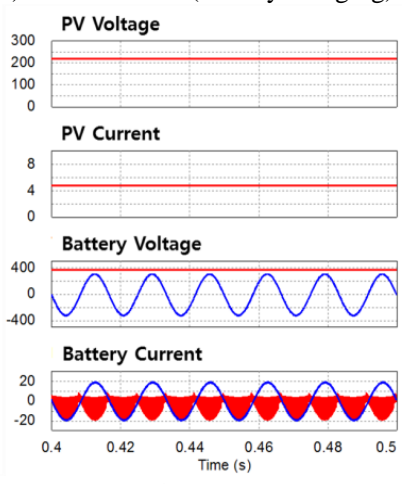

(d) State 2

Fig. 9. Simulation of PV-PPC system by state. 


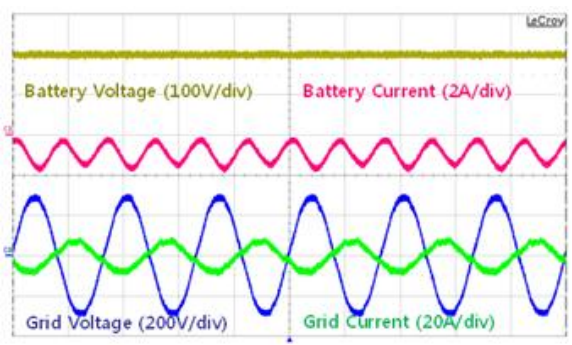

(a) State 0

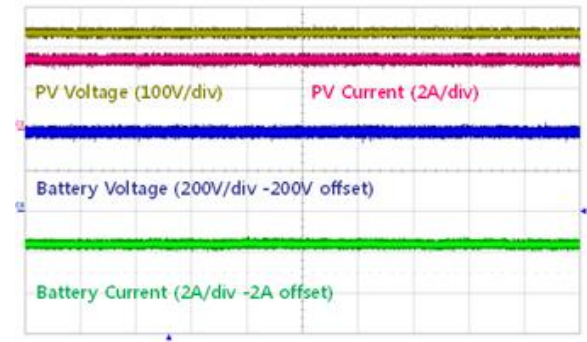

(b) States 1 and 3 (Battery charging)

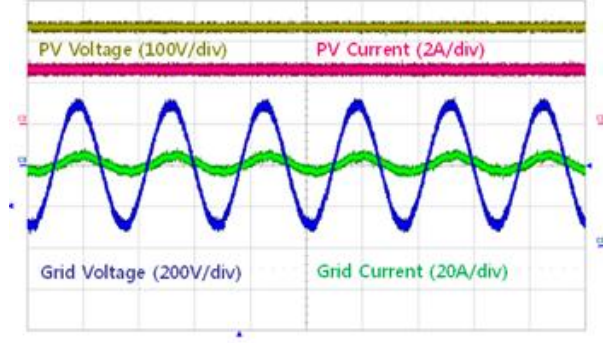

(c) States 1 and 3 (Gird generating)

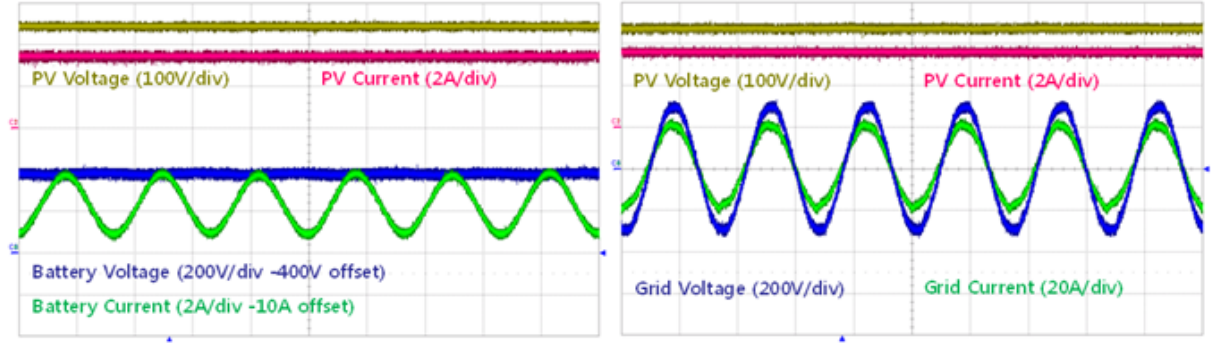

(d) State 2

Fig. 10. Experiment of the PV-PPC system by state.

\section{Simulation and Experiment}

The simulation was performed by using the PSIM (9.0 PowerSim) to implement the operation of the PV-PPC system before the experiment. The simulated results are shown in Fig. 9. In Fig. 9 (a), the power of the PV $(1100 \mathrm{~W})$ is recharged in the battery, and Fig. 9 (b) shows the waveforms that the power of the PV is generating into the system. In the Fig. 9 (c), the PV and the battery are generating into the system. Fig. 9 (d) shows the recharging of the battery from the system by using the cheap time zone at night. Fig. 10 shows the experimental results which are similar to the simulation. In the experiment, the TMS320F28335 was used to control the system.

\section{Conclusion}

A PV-PPC power generation system with the peak load cutting function to reduce the peak load power effect of the power system is presented in this paper. Simulation analysis was performed using the PSIM software to validate the different operational modes of the power flow of the proposed PV-PPC system during the on-peak and off-peak periods. During on-peak operation, the power is managed to flow from the $\mathrm{PV}$ and the storage battery to help meet peak demands and reduce daily utility peak demands.

During the periods of off-peak demand, the PV power can be stored in the system battery or fed to the utility grid. The feasibility of the proposed system has been verified practically through experimental results. Through the simulation and experimental results given in this paper, the system can effectively alleviate the peak load power hours efficiently which shows its potential to reduce utility electricity costs. 


\section{References}

[1] Wai RJ. High-performance stand-alone photovoltaic generation system. IEEE Trans. Industrial Electronics, 2008; 55(1):240250.

[2] Shimizu T, Hirakata M, Kamezawa T, Watanabe H. Generation control circuit for photovoltaic modules. IEEE Trans. Power Electronics, 2001; 16(3):293-300.

[3] Leyva R, Alonso C, Queinnec I. et al. MPPT of photovoltaic systems using extremum-seeking control. IEEE Trans. Aerospace and Electronic Systems, 2006; 42(1):249-258.

[4] Kojabadi H M. A novel DSP-based current-controlled PWM strategy for single phase grid connected inverters. IEEE Trans. Power Electronics, Jul. 2006; 21:985-993.

[5] Zhi LD. Improved direct power control of grid-connected DC/AC converters. IEEE Trans. Power Electronics, May 209; 24:1280-1292.

[6] Min BD. A novel grid-connected PV PCS with new high efficiency converter. Journal of Power Electronics, Oct. 2008; 8:309-316

[7] Thangaprakash S. Unified MPPT control strategy for Z-source inverter based photovoltaic power conversion systems. Journal of Power Electronics, 2012; 12(1):172-180.

[8] Choi W-Y, Choi J-Y. High-efficiency power conditioning system for grid-connected photovoltaic modules. Journal of Power Electronics, 2008; 11(4):561-567.

[9] Kim YC, Jin L, Lee J, Choi J. Direct digital control of single-phase AC/DC PWM converter system. Journal of Power Electronics, 2010; 10(5):518-527.

[10] Kim H, Parkhideh B, Bongers TD, Gao H. Reconfigurable solar converter: a single-stage power conversion PV-battery system. IEEE Trans. Power Electronics, 2013; 28(8):3788-3797.

[11] Choi B-Y, Noh Y-S, Ji Y-H, et al. Battery-integrated power optimizer for PV-battery hybrid power generation system. In: Proc. of IEEE Vehicle Power and Propulsion Conference (VPPC), 2012:1343-1348.

[12] Nge CL, et al. PV with battery in smart grid paradigm: Price-based energy management system. In: Proc. of 38th IEEE Photovoltaic Specialists Conference (PVSC), 2012:575-579. 